\title{
Microstructure evolution and its effect on mechanical properties of cast Ti48 Al6 NbrSi alloys
}

\author{
Qin Xu', Hong-ze Fang' ${ }^{2}$, Chao Wu', Qi Wang ${ }^{2}$, Hong-zhi Cui ${ }^{3}$, *Rui-run Chen ${ }^{2,3}$ \\ 1. School of Mechanical and Electrical Engineering, Henan University of Technology, Zhengzhou 450001, China \\ 2. National Key Laboratory for Precision Hot Processing of Metals, Harbin Institute of Technology, Harbin 150001, China \\ 3. School of Materials Science and Engineering, Shandong University of Science and Technology, Qingdao 266590, China
}

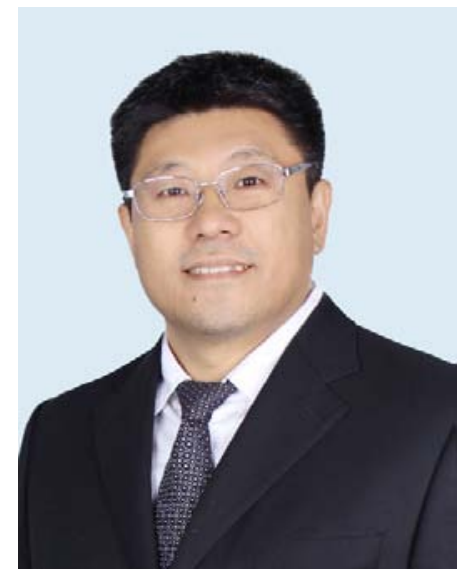

*Rui-run Chen

Ph.D., Professor, doctoral supervisor, Vice Director of the Interdiscipline Research Center of Harbin Institute of Technology. He is the the winner of the National Science Fund for Distinguished Young Scholars, and one of the leading talents of the scientific and technological innovation of the "Ten-thousand Talents Program". His research interests mainly focus on the solidification theory and casting technology of titanium aluminum alloys, niobium silicon alloys, high entropy alloys, metal based hydrogen storage materials, and solar grade silicon. To date, he has published more than $240 \mathrm{SCl}$ indexed papers, and has been authorized 24 patents for inventions of China.

E-mail: ruirunchen@hit.edu.cn

Received: 2020-06-24

Accepted: 2020-09-30
Abstract: In order to improve mechanical properties of TiAINb alloys, different contents of silicon were added into Ti48Al6Nb alloy. The Ti48Al6NbxSi $(x=0,0.1$, $0.2,0.3,0.4$ and 0.5 , at. $\%$ ) alloys were prepared by vacuum arc melting. The phase constitution, microstructure evolution and mechanical properties of the alloys were studied. Results show that the Ti48Al6NbxSi alloys consist of $\mathrm{Y}$-TiAl phase, $\mathrm{a}_{2}-\mathrm{Ti}_{3} \mathrm{Al}$ phase and $\mathrm{B} 2$ phase, and $\mathrm{Ti}_{5} \mathrm{Si}_{3}$ silicide phase is formed when the addition of silicon is higher than $0.3 a t . \%$. The addition of silicon leads to the decrease in $\mathrm{y}$ phase and increase in $\alpha_{2}$ phase. The formation of silicide decreases the amount of $\mathrm{Nb}$ dissolved in the TiAl matrix, and therefore decreases B2 phase. Compressive tests show that the ultimate strength of the alloys increases from 2,063 MPa to 2,281 MPa with an increase in silicon from 0 to 0.5 at. $\%$, while the fracture strain decreases from $34.7 \%$ to $30.8 \%$. The increase of compressive strength and decrease of fracture strain can be attributed to the decrease of $\mathrm{B} 2$ phase and the formation of $\mathrm{Ti}_{5} \mathrm{Si}_{3}$ phase by the addition of silicon. The strengthening mechanism is changed from solid solution strengthening when the addition of silicon is less than 0.3 at.\% to combination of solid solution strengthening and secondary phase strengthening when the addition of silicon is higher than $0.3 a t . \%$.

Key words: TiAl-based alloy; microstructure; mechanical property; strengthening CLC numbers: TG146.23; Document code: A; Article ID: 1672-6421(2020)06-416-07

$\mathrm{T}$ he $\gamma$-TiAl based alloys have been widely used in aeronautic and aerospace engineering for its low density, high melting temperature and high specific strength ${ }^{[1-3]}$. They are considered as candidate materials of turbine blades to replace the Ni-based high temperature alloys due to their good creep and oxidation resistance at elevated temperature ${ }^{[4-5]}$. However, the poor ductility and low fracture toughness of the $\gamma$-TiAl based alloys at room temperature limit their further application ${ }^{[6-8]}$.

Many research works show that addition of $\mathrm{Nb}$ can improve the room temperature plasticity, liquidus and high temperature oxidation behavior of TiAl alloys ${ }^{[8-9]}$. The high-Nb TiAl alloys can maintain a metastable $\mathrm{B} 2$ phase because $\mathrm{Nb}$ is a $\beta$-stabilizing element ${ }^{[10-13]}$. B2 phase with a body centered cubic lattice structure is softer than $\gamma$ (TiAl) and $\alpha_{2}\left(\mathrm{Ti}_{3} \mathrm{Al}\right)$ phases in the TiAl alloys, can serve as the grain-refinement and plastic-enhancement component at elevated temperature ${ }^{[3,14-15]}$. Nb can increase the high temperature strength, ductility, and toughness of TiAl alloys. The service temperature of high-Nb TiAl alloys can exceed $800^{\circ} \mathrm{C}^{[16-17]}$.

Silicon is one of the most important alloying elements of TiAl alloys ${ }^{[16,18-20]}$. $\mathrm{Ti}_{5} \mathrm{Si}_{3}$ phases are formed during the solidification process of TiAl alloys when the addition of silicon reaches a certain level. $\mathrm{The} \mathrm{Ti}_{5} \mathrm{Si}_{3}$ phases, which are considered as thermodynamically stable reinforce particles, show very strong interfacial bonding with the TiAl matrix and promote the oxidation resistance of TiAl alloys ${ }^{[16,21]}$. The $\mathrm{Ti}_{5} \mathrm{Si}_{3}$ phase has a high hardness (about $11.3 \mathrm{GPa}{ }^{[22]}$, and can act as the strengthening phase in the TiAl alloys, preventing the high temperature deformation of TiAl alloys, and thus improving the plasticity and high temperature strength ${ }^{[23-24]}$. 
High-Nb TiAl alloy, Ti48Al6Nb (at.\%) with different addition amounts of silicon was prepared in the present study. The effects of silicon on the microstructure evolution, phase constitution, and mechanical properties of the high-Nb TiAl alloy ingots were studied.

\section{Experimental}

The Ti48Al6Nb $x$ Si (at. $\%, x=0,0.1,0.2,0.3,0.4$ and 0.5 ) TiAlbased alloy ingots with different silicon additions were melted in a vacuum arc melting furnace using tungsten electrode. The raw materials were sponge titanium, particle silicon, ingot aluminum and $\mathrm{Al}-70 \mathrm{wt} . \% \mathrm{Nb}$ intermediate alloy. The actual weight of aluminum is 1.04 times of the calculated one for it was easily burned and volatilized. The ingots were melted five times in the argon atmosphere to ensure the composition homogeneity.

Each solidified ingot was cut into two halves from the center by electrical-discharge wire cutting machine (DK7732). Three columnar specimens with dimensions of $\Phi 4 \mathrm{~mm} \times 6 \mathrm{~mm}$ were cut from one half of the ingot. A specimen with thickness of $8 \mathrm{~mm}$ was cut from near the center of the other half for microstructure observation. The specimens for microstructure observation were ground and mechanically polished, and then etched with standard Kroll's reagent of $3 \mathrm{ml} \mathrm{HF}, 10 \mathrm{ml}$ $\mathrm{HNO}_{3}$ and $100 \mathrm{ml} \mathrm{H}_{2} \mathrm{O}$ for about $10 \mathrm{~s}$. The phase constitution was identified by an X-ray diffractometer (XRD, Panalytical, Empyrean $\mathrm{Cu} \mathrm{K} \alpha, 20 \mathrm{Kv}, 8^{\circ} \cdot \mathrm{min}^{-1}$ ), and the $2 \theta$ scattering range of $20^{\circ}$ to $90^{\circ}$. Scanning electron microscopy (SEM, JEOL, JXA-8230) was used to study the microstructure employing backscatter electron (BSE) mode. Energy dispersion spectrum (EDS) was applied to measure the elemental composition of different phases. The volume fraction of different phases was measured using an image analyzer. Compression tests of columnar specimens were performed using a computer controlled Instron 5569 mechanical testing machine. At least 3 specimens were measured for each alloy with an compression rate of $0.5 \mathrm{~mm} \cdot \mathrm{min}^{-1}$.

\section{Results and discussion}

\subsection{Phase analysis}

Figure 1 shows the XRD patterns of Ti48A16Nb alloy with different additions of silicon. It can be seen that the alloys are composed of $\gamma$-TiAl phase, $\alpha_{2}-\mathrm{Ti}_{3} \mathrm{Al}$ phase and $\mathrm{B} 2$ phase, and no obvious $\mathrm{Ti}_{5} \mathrm{Si}_{3}$ diffraction peaks are observed after adding silicon. The intensity of diffraction peaks for $\gamma$ phase is the highest [Fig. 2(a)] for the Ti48Al6Nb alloy with no Si addition, showing that the addition of silicon will reduce the amount of $\gamma$ phase. The intensity of diffraction peaks for $\alpha_{2}$ phase is the lowest [Fig. 2(b)] for the alloy with no $\mathrm{Si}$, indicating that the amount of $\alpha_{2}$ phase is increased by addition of silicon.

Silicon is typical $\alpha$ phase stable element which can reduce the zone of $\beta$ phase in the TiAl binary phase diagram ${ }^{[20]}$. The aluminum equivalent of silicon in TiAl alloys is -2.8 . Therefore, TiAl alloys with addition of silicon will move to

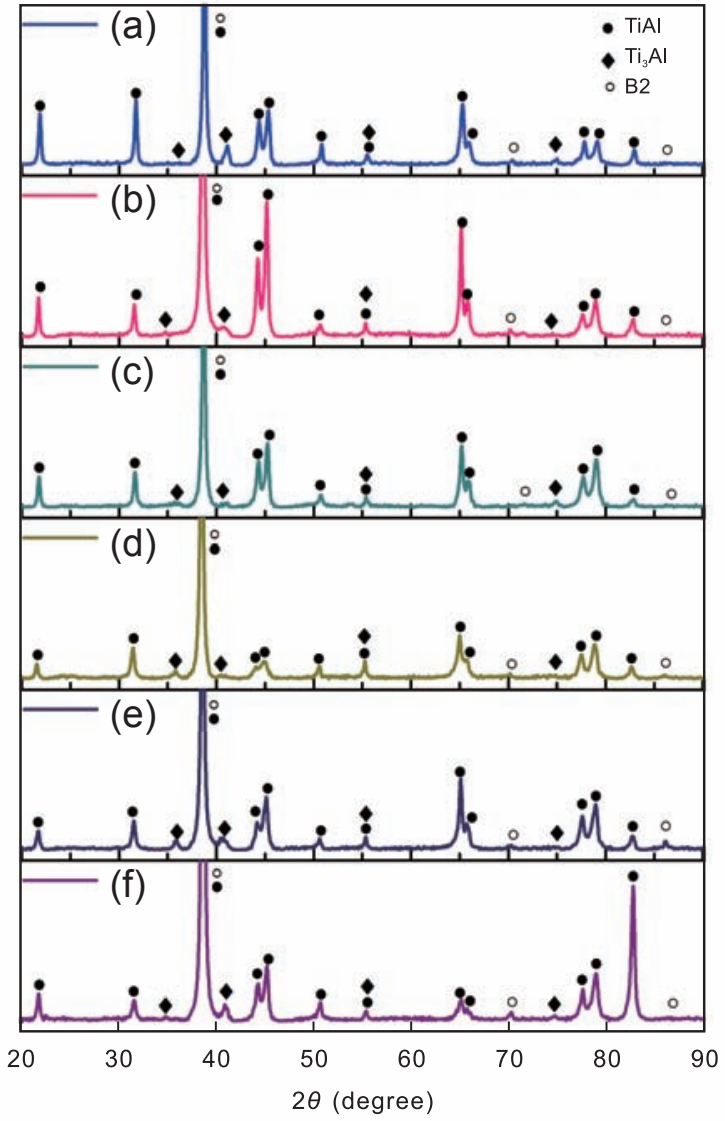

Fig. 1: XRD patterns of Ti48Al6NbxSi alloys: (a) $x=0$; (b) $x=0.1$; (c) $x=0.2$; (d) $x=0.3$; (e) $x=0.4$; (f) $x=0.5$

the lower aluminum content parts of the TiAl binary phase diagram. Thus, the amount of $\gamma$ phase decreases and $\alpha_{2}$ phase increases by adding silicon to the Ti48Al6Nb alloy according to the XRD results. In addition, the solubility of silicon in the TiAl alloys is low, for it is an interstitial element in the alloys. Furthermore, the mixing enthalpy of silicon-titanium is very low $\left(-66 \mathrm{~kJ} \cdot \mathrm{mol}^{-1}\right)$, thus, it is easy for silicon to form intermetallics in the TiAl alloys with higher content of silicon. However, the silicide intermetallics are not observed in the present alloys, which is possibly attributed to their tiny amount.

\subsection{Microstructure}

Figure 3 shows the microstructures of Ti48Al6 NbxSi alloys with different additions of silicon. It can be seen that the morphology of Ti48Al6 $\mathrm{Nb} x \mathrm{Si}$ alloys changes from coarse columnar grains to fine equiaxed grains when the addition of silicon increases from 0 to 0.5 at. $\%$. The primary and secondary dendrite lengths of Ti48A16NbxSi alloys are summarized in Table 1. The Ti48A16Nb alloy without addition of silicon shows coarse columnar grains, and the bright B2 phase forms in the center of the dendrite structures, as shown in Fig. 3(a). The primary and secondary dendrite lengths of Ti48Al6Nb are $246 \mu \mathrm{m}$ and 152 $\mu \mathrm{m}$, respectively. The grains evolve to refined columnar grains when the addition of silicon is 0.1at.\%, as shown in Fig. 3(b), and the primary and secondary dendrite lengths of Ti48Al6Nb0.1Si are decreased to $178 \mu \mathrm{m}$ and $108 \mu \mathrm{m}$, respectively. When the addition of silicon is increased to 0.2 at. $\%$, the primary and secondary dendrite lengths of Ti48A16Nb0.2Si are further 

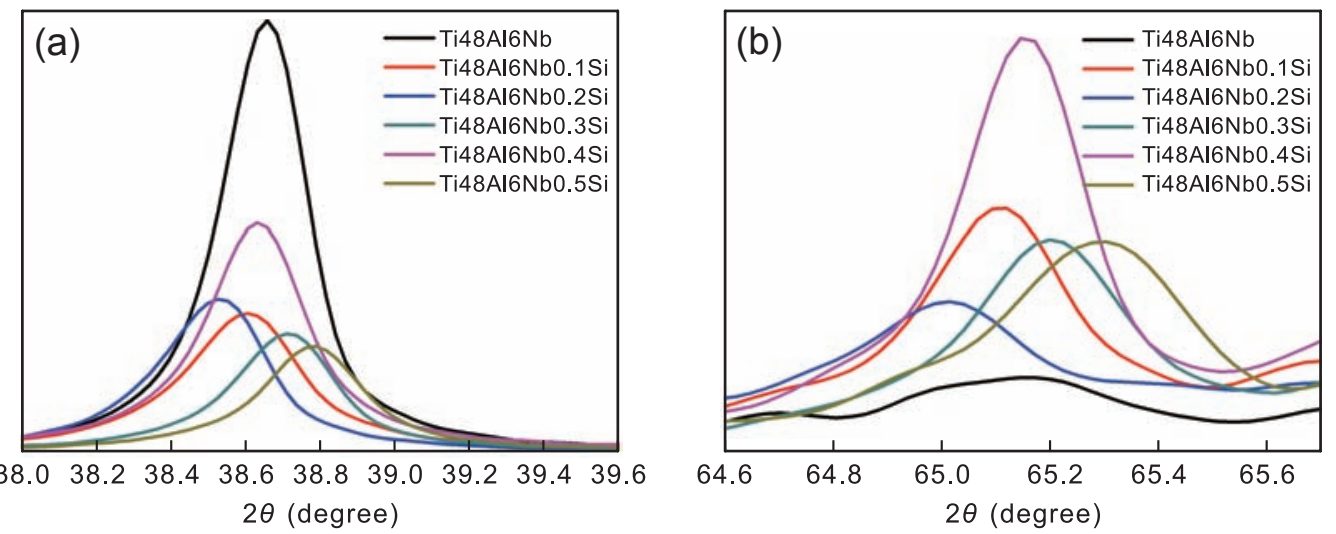

Fig. 2: Diffraction peaks of $\mathrm{Y}-\mathrm{TiAl}$ phase and $\alpha_{2}-\mathrm{Ti}_{3} \mathrm{Al}$ phase: (a) $\mathrm{Y}$-TiAl phase; (b) $\alpha_{2}-\mathrm{Ti}_{3} \mathrm{Al}$ phase
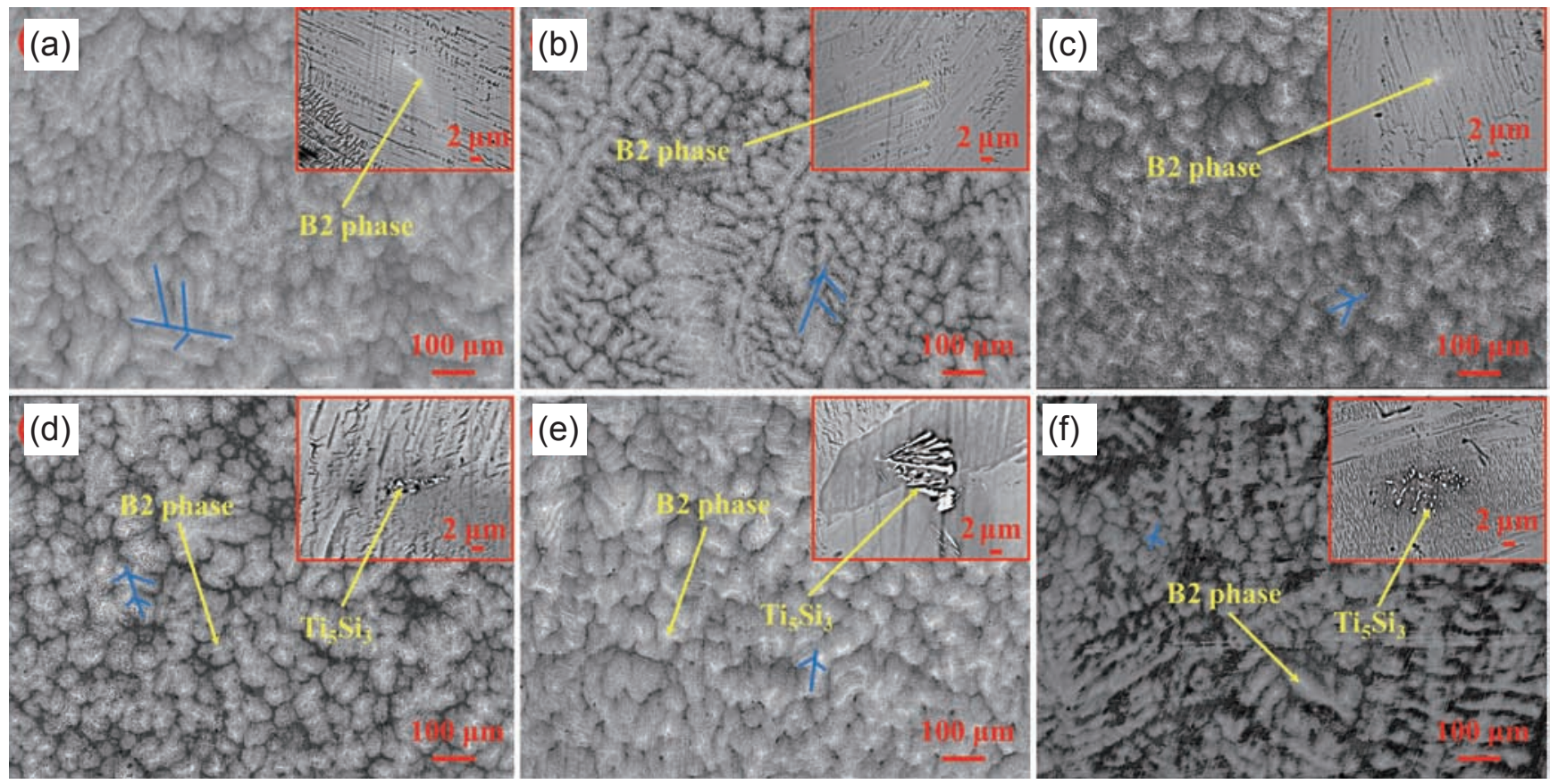

Fig. 3: Microstructure of Ti48Al6NbxSi alloys: (a) $x=0$; (b) $x=0.1$; (c) $x=0.2$; (d) $x=0.3$; (e) $x=0.4$; (f) $x=0.5$

Table 1: Dendrite length and volume fraction of $\mathrm{B} 2$ and $\mathrm{Ti}_{5} \mathrm{Si}_{3}$ for Ti48AI6NbxSi alloys

$\begin{array}{ccccc}\begin{array}{c}\text { Si content } \\ (\text { at. } \%)\end{array} & \begin{array}{c}\text { Primary dendrite } \\ \text { length }(\mu \mathrm{m})\end{array} & \begin{array}{c}\text { Secondary dendrite } \\ \text { length }(\mu \mathrm{m})\end{array} & \begin{array}{c}\mathrm{B2} \\ (\mathrm{vol} . \%)\end{array} & \begin{array}{c}\mathrm{Ti}_{5} \mathrm{Si}_{3} \\ (\mathrm{vol} . \%)\end{array} \\ 0 & 246 & 152 & 2.7 & 0 \\ 0.1 & 178 & 108 & 2.5 & 0 \\ 0.2 & 149 & 62 & 2.6 & 0 \\ 0.3 & 132 & 50 & 2.3 & 1.2 \\ 0.4 & 100 & 40 & 2.2 & 1.6 \\ 0.5 & 60 & 32 & 1.9 & 2.1\end{array}$

refined to $149 \mu \mathrm{m}$ and $62 \mu \mathrm{m}$, as shown in Fig. 3(c). When the addition of silicon increases to $0.3 \mathrm{at} . \%, \mathrm{Ti}_{5} \mathrm{Si}_{3}$ silicide phase particles form at the grain boundaries [Fig. 3(d)], and the grains of Ti48A16Nb0.3Si are further refined. When the addition of silicon increases to 0.4 at. $\%$ and $0.5 \mathrm{at} . \%$, the dendrite structure of the alloys changes to fine equiaxed grains
[Figs. 3(d) and (f)]. The primary and secondary dendrite lengths of Ti48Al6Nb0.5 Si are decreased to $60 \mu \mathrm{m}$ and $32 \mu \mathrm{m}$.

The volume fractions of $\mathrm{B} 2$ phase and $\mathrm{Ti}_{5} \mathrm{Si}_{3}$ silicide phase of Ti48Al6 NbxSi alloys are calculated by counting the pixel area of Photoshop software, and the results are listed in Table 1. It shows that the volume fraction of B2 phase for the 
Ti48Al6NbxSi alloys has an obvious decreasing trend when the addition of silicon increases from 0 to 0.5 at.\%. The $\mathrm{Ti}_{5} \mathrm{Si}_{3}$ silicide phase forms when the content of silicon is no less than 0.3 at. $\%$. The volume fraction of $\mathrm{Ti}_{5} \mathrm{Si}_{3}$ silicide phase for Ti48Al6Nb0.3Si alloy is about $1.2 \%$, and the volume fraction of $\mathrm{Ti}_{5} \mathrm{Si}_{3}$ silicide phase for Ti48Al6Nb0.4Si alloy is increased to $1.6 \%$. When the content of silicon is increased to $0.5 \mathrm{at} . \%$, the volume fraction of $\mathrm{Ti}_{5} \mathrm{Si}_{3}$ silicide phase is increased to $2.1 \%$. Meanwhile the volume fraction of B2 phase is slightly decreased to about $1.9 \%$.

Figure 4 shows the microstructures of Ti48Al6 NbxSi alloys with a higher magnification. Different phases of the alloys are labeled with different marks. The elemental compositions of the bright B2 phase (marked with A), the grey $\gamma$ phase area (marked with B), the matrix $\alpha_{2} / \gamma$ colony (marked with C) and the silicide phase (marked with D) are summarized in Table 2. It shows that the bright $\mathrm{B} 2$ phase is rich in $\mathrm{Nb}$ and poor in $\mathrm{Al}$, while the grey area is rich in $\mathrm{Al}$ and poor in $\mathrm{Nb}$ for all the Ti48Al6 $\mathrm{Nb} x \mathrm{Si}$ alloys. There is no obvious change in the content of $\mathrm{Nb}$ dissolved in the $\alpha_{2} / \gamma$ colonies of Ti48Al6 NbxSi alloys. The $\mathrm{Nb}$ in B2 phase for $\mathrm{Ti} 48 \mathrm{Al} 6 \mathrm{Nb} x \mathrm{Si}$ alloys is decreased when increasing the addition of silicon from 0 to 0.5 at. $\%$. By adding silicon with 0.1 at. $\%$ and 0.2 at. $\%$, the content of $\mathrm{Nb}$ dissolved in $\mathrm{B} 2$ becomes less than that with no silicon. At the same time, the content of $\mathrm{Nb}$ is increased in the grey area. When the content of silicon is increased to 0.3 at. $\%$, the content of $\mathrm{Nb}$ dissolved in $\mathrm{B} 2$ phase is decreased to $6.97 \%$, and that dissolved in the grey phase is obviously decreased to $4.64 \%$, for a certain amount of $\mathrm{Nb}$ is dissolved in the $\mathrm{Ti}_{5} \mathrm{Si}_{3}$ silicide phase. When the addition of silicon increases to 0.4 at. $\%$ and 0.5 at. $\%$, there is no obvious change in the content of $\mathrm{Nb}$ dissolved in $\mathrm{B} 2$ phase and grey phase. However, the content of $\mathrm{Nb}$ dissolved in $\mathrm{Ti}_{5} \mathrm{Si}_{3}$ silicide phase is apparently increased from $4.54 \%$ to $6.27 \%$ when the addition of silicon increases from 0.3 at. $\%$ to 0.5 at. $\%$.
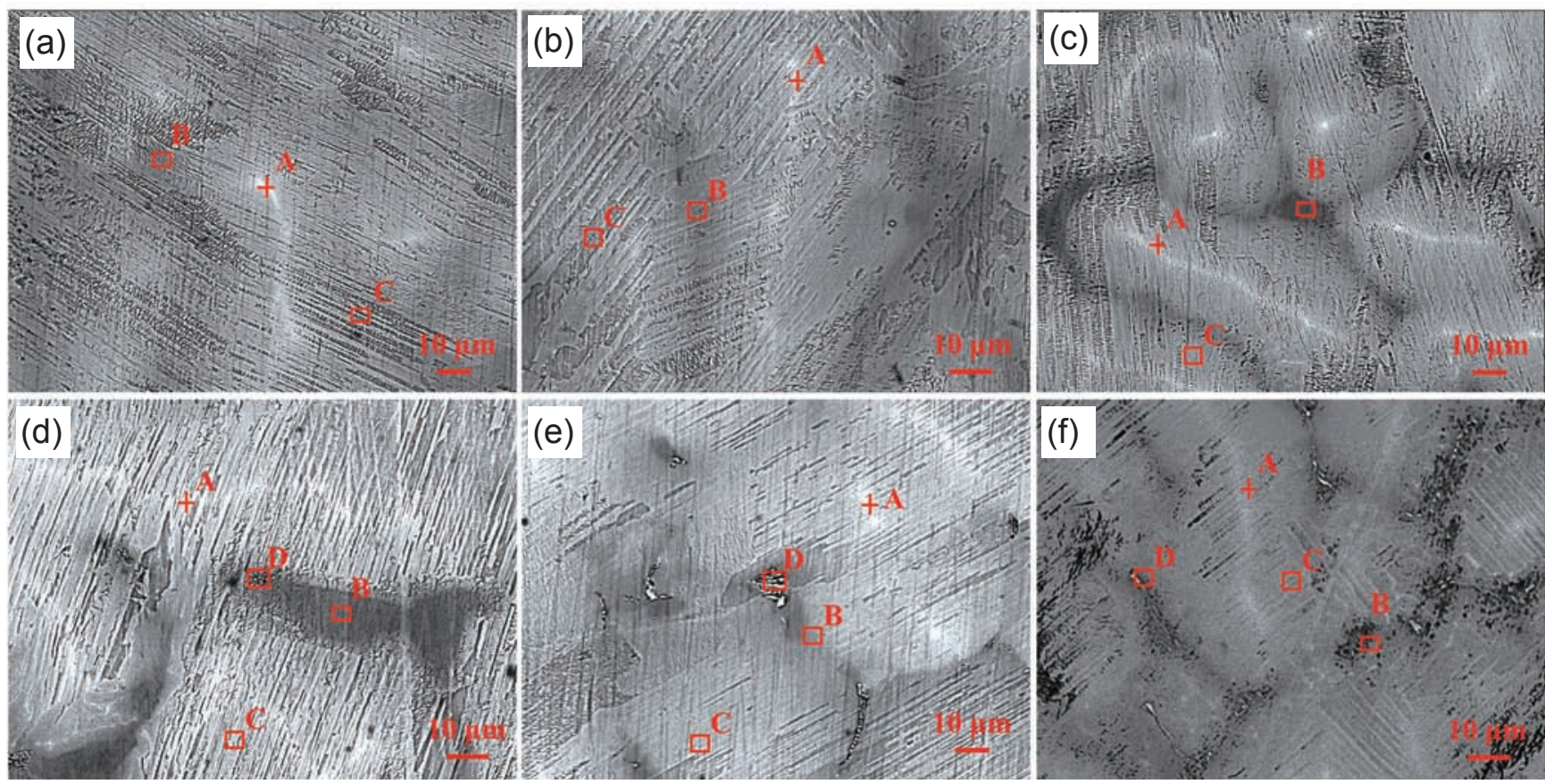

Fig. 4: Microstructure of Ti48AI6NbxSi alloys: (a)

(a) $x=0$; (b)

(b) $x=0.1 ;$ (c) $x=0.2$

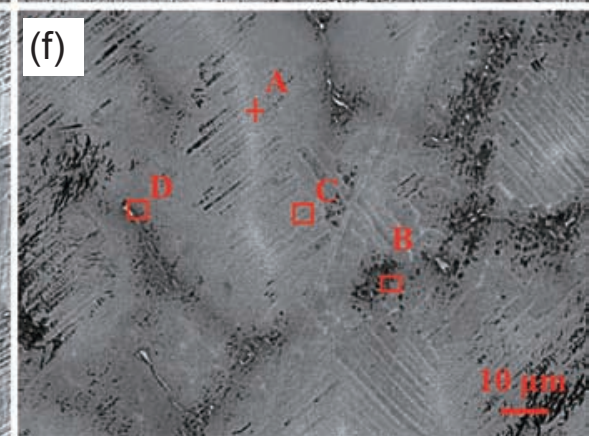

B2 phase in the TiAl alloys is a metastable phase transformed from the high temperature stable $\beta$ phase and can improve the high temperature deformation behaviors of alloys. B2 phase forms when the $\beta$ phase stable element is segregated between lamellae or in the lamellar colonies ( $\beta$-segregation). However, silicon can partially substitute $\mathrm{Nb}$ in $\mathrm{B} 2$ phase, thus the addition of $\mathrm{Si}$ can decrease the content of $\mathrm{Nb}$ in the $\mathrm{B} 2$ phase and increase the content of $\mathrm{Nb}$ in the matrix alloy before forming $\mathrm{Ti}_{5} \mathrm{Si}_{3}$. Therefore, the amount of B2 phase decreases when silicon is added into the Ti48Al6Nb alloy ( $x=0.1 \mathrm{at} . \%$, 0.2 at. $\%$ ). When the addition of silicon is increased to $0.3 \%$, $\mathrm{Ti}_{5} \mathrm{Si}_{3}$ phase begins to form in the alloy. The formation of $\mathrm{Ti}_{5} \mathrm{Si}_{3}$ phase can dissolve a certain content of $\mathrm{Nb}$ (shown in Table 2), and therefore lead to a decrease in the amount of $\mathrm{Nb}$ dissolved in the TiAl matrix alloy. Thus, the amount of B2 phase decreases. When the addition of silicon is further increased to 0.4 at. $\%$ and 0.5 at. $\%$, the increment of silicon leads to an obvious increase in the amount of $\mathrm{Ti}_{5} \mathrm{Si}_{3}$ phase. Thus, the total amount of element $\mathrm{Nb}$ dissolved in $\mathrm{Ti}_{5} \mathrm{Si}_{3}$ phase increases, and therefore leads to a decrease of $\mathrm{B} 2$ phase in the TiAl alloy.

\subsection{Mechanical properties}

The uniaxial compressive test results of Ti48Al6 NbxSi alloys with different additions of silicon are shown in Fig. 5 and Table 3. The compressive strength of the TiAl alloys increases with increasing the content of silicon, while the fracture strain of the alloys first slightly increases and then has a decreasing trend. The compressive strength of Ti48 Al6 Nb alloy is $2,063 \mathrm{MPa}$ and the fracture strain is $34.7 \%$. When adding 0.1 at.\% silicon, the compressive strength of Ti48A16Nb0.1Si alloy increases to $2,091 \mathrm{MPa}$ and the fracture strain is slightly increased to $35.2 \%$. The compressive strength of 
Table 2: EDS results for different positions of Ti48Al6NbxSi alloys

\begin{tabular}{|c|c|c|c|c|c|}
\hline $\begin{array}{l}\text { Si content } \\
\text { (at.\%) }\end{array}$ & Position & Ti (at.\%) & Al (at.\%) & Nb (at. \%) & Si (at. \%) \\
\hline \multirow{3}{*}{0} & A & 47.71 & 43.86 & 8.43 & \\
\hline & B & 44.78 & 51.06 & 4.06 & \\
\hline & C & 44.82 & 48.96 & 6.22 & \\
\hline \multirow{3}{*}{0.1} & A & 44.87 & 47.62 & 7.30 & 0.21 \\
\hline & B & 44.06 & 50.95 & 4.82 & 0.17 \\
\hline & C & 45.50 & 48.42 & 5.99 & 0.09 \\
\hline \multirow{4}{*}{0.2} & A & 45.10 & 47.45 & 7.12 & 0.33 \\
\hline & B & 46.03 & 46.61 & 7.10 & 0.26 \\
\hline & C & 44.51 & 49.46 & 5.95 & 0.08 \\
\hline & A & 45.91 & 46.28 & 6.97 & 0.85 \\
\hline \multirow{3}{*}{0.3} & B & 42.75 & 52.08 & 4.64 & 0.52 \\
\hline & C & 46.27 & 47.20 & 6.19 & 0.34 \\
\hline & D & 47.53 & 31.77 & 4.54 & 16.16 \\
\hline \multirow{4}{*}{0.4} & A & 46.60 & 46.39 & 6.64 & 0.37 \\
\hline & B & 42.69 & 52.19 & 3.91 & 1.20 \\
\hline & C & 44.53 & 48.77 & 6.24 & 0.46 \\
\hline & D & 49.86 & 23.70 & 6.12 & 20.33 \\
\hline \multirow{4}{*}{0.5} & A & 45.60 & 46.76 & 6.99 & 0.65 \\
\hline & B & 43.14 & 51.55 & 4.79 & 0.53 \\
\hline & C & 44.65 & 48.94 & 6.06 & 0.35 \\
\hline & D & 49.10 & 21.08 & 6.27 & 23.55 \\
\hline
\end{tabular}

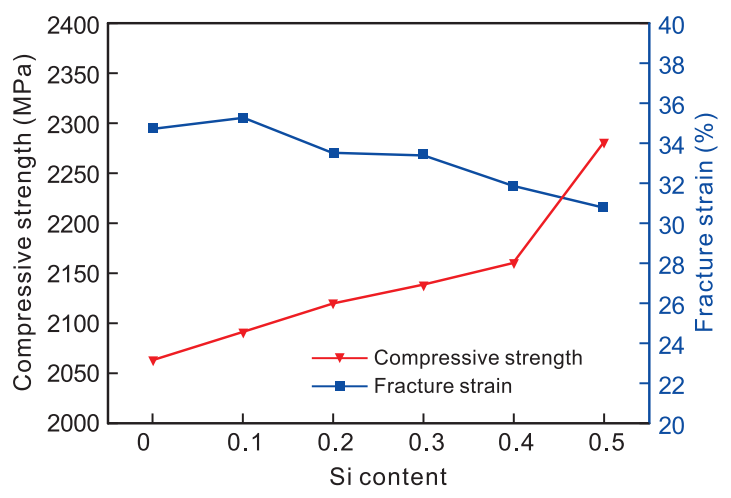

Fig. 5: Compressive properties of $\mathrm{Ti} 48 \mathrm{Al} 6 \mathrm{Nb} x \mathrm{Si}$ alloys: (a) $x=0$; (b) $x=0.1$; (c) $x=0.2$; (d) $x=0.3$; (e) $x=0.4$; (f) $x=0.5$

Ti48Al6Nb0.2Si alloy increases to 2,120 MPa when the content of silicon is $0.2 \mathrm{at} . \%$, and the fracture strain is decreased to $33.5 \%$. When the content of silicon is $0.5 \mathrm{at} . \%$, the compressive strength of the TiAl alloy reaches its maximum of 2,281
Table 3: Compressive properties of Ti48AI6NbxSi alloys

\begin{tabular}{ccc|}
$\begin{array}{c}\text { Si content } \\
\text { (at.\%) }\end{array}$ & Strength (MPa) & Strain (\%) \\
\hline 0 & 2,063 & 34.73 \\
0.1 & 2,091 & 35.23 \\
0.2 & 2,120 & 33.48 \\
0.3 & 2,138 & 33.39 \\
0.4 & 2,160 & 31.84 \\
0.5 & 2,281 & 30.76 \\
\hline
\end{tabular}

$\mathrm{MPa}$. At the same time, the fracture strain of the alloy reaches its minimum of $30.8 \%$. When adding 0.5 at. $\%$ silicon, the compressive strength of the Ti48Al6Nb alloy improves about $11 \%$ from 2,063 $\mathrm{MPa}$ to 2,281 $\mathrm{MPa}$. In contrast, the addition of Si leads to a decrease in the compression strain of the alloys from $34.7 \%$ to $30.8 \%$ when the content of $\mathrm{Si}$ increases from 0.1 at. $\%$ to 0.5 at. $\%$.

\subsection{Discussion}

The aforementioned phenomenon of the compressive strength and fracture strain of the Ti48Al6NbxSi alloys can be attributed to the decrease of $\mathrm{B} 2$ phase and the formation of $\mathrm{Ti}_{5} \mathrm{Si}_{3}$ phase by the addition of silicon.

As has been stated above, the addition of silicon will increase solubility of $\mathrm{Nb}$ in the Ti48Al6 NbxSi alloys when the content of silicon is less than $0.3 \mathrm{at} . \%$, and $\mathrm{Ti}_{5} \mathrm{Si}_{3}$ phase particles will form on the lamellar colony interface of the Ti48Al6 NbxSi alloys when the content of silicon is $\geq 0.3 \mathrm{at} . \%$. This is because the solubility of silicon in the $\alpha$ phase of TiAl alloys is very low. During the solidification process, silicon will be squeezed from $\alpha$ phase and segregated in the liquid melt between the dendrites. When the content of silicon is higher than $4 \%$ in the segregation area, $\mathrm{Ti}_{5} \mathrm{Si}_{3}$ phase will form at the interface of the colonies ${ }^{[25-27]}$. Thus, when the content of silicon is $<0.3 \mathrm{at} . \%$, the solidification process of the Ti48Al6NbxSi alloys is as follows, $\mathrm{L} \rightarrow \mathrm{L}+\beta \rightarrow$ $\mathrm{L}+\alpha+\beta_{\mathrm{r}} \rightarrow \alpha+\beta_{\mathrm{r}} \rightarrow \alpha+\gamma+\beta_{\mathrm{r}} \rightarrow\left(\alpha_{2}+\gamma\right)+\gamma+\mathrm{B} 2$. When the content of silicon is $\geq 0.3 \%$, the solidification process of the Ti48Al6 NbxSi alloys is as follows, $\mathrm{L} \rightarrow \mathrm{L}+\beta \rightarrow \mathrm{L}+\alpha+\beta_{\mathrm{r}} \rightarrow \alpha+\beta_{\mathrm{r}}+\mathrm{Ti}_{5} \mathrm{Si}_{3} \rightarrow$ $\alpha+\gamma+\beta_{\mathrm{r}}+\mathrm{Ti}_{5} \mathrm{Si}_{3} \rightarrow\left(\alpha_{2}+\gamma\right)+\gamma+\mathrm{B} 2+\mathrm{Ti}_{5} \mathrm{Si}_{3}$.

Figure 6 shows the schematic diagram of microstructure evolution during the solidification process of Ti48Al6 $\mathrm{Nb}$ alloys with different contents of silicon. As shown in Fig. 6(a1)(a4), when the content of silicon is $x<0.3$ at. $\%, \beta$ phase with higher solubility of $\mathrm{Nb}$ firstly precipitates from the melt. At the same time, $\mathrm{Nb}$ migrates from the remaining melt into $\beta$ phase, and Si will migrate from $\beta$ phase into the remaining melt [Fig. 6(a1)]. Then $\alpha$ phase forms by the peritectic reaction, $\mathrm{L}+\beta \rightarrow \alpha$. Meanwhile, $\mathrm{Nb}$ atoms segregate in $\alpha$ phase and form $\beta$-segregation [Fig. 6(a2)]. As the solidification process proceeds, many $\alpha$ colonies with $\beta$-segregation form after the melt is consumed [Fig. 6(a3)]. After that, the $\alpha_{2} / \gamma$ lamellae form by the solid-state phase transformation from $\alpha$ phase, and the residual $\beta$ phases ( $\beta$-segregation areas) transfer into B2- 


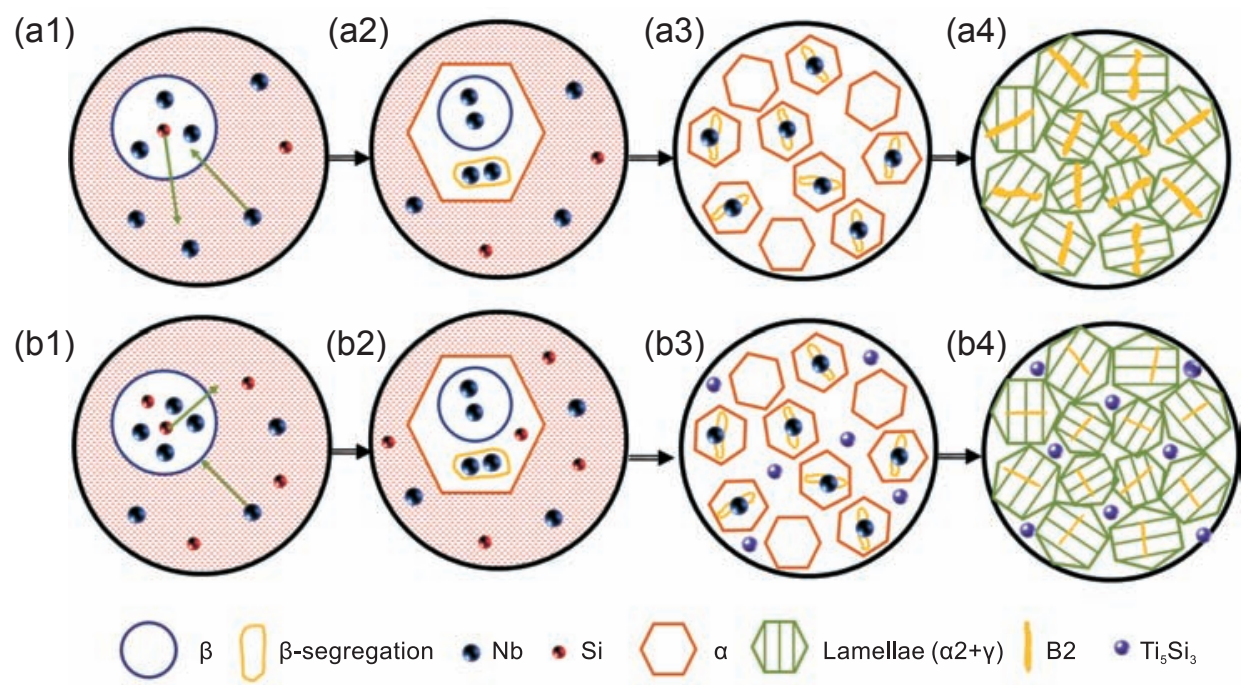

Fig. 6: Schematic diagram showing microstructure evolution of Ti48AI6NbxSi alloys:

(a1) - (a4): $x<0.3 a t . \%$; (a1) formation of $\beta$ phase; (a2) formation of $\alpha$ phase with $\beta$-segregation;

(a3) $\alpha$ colonies with $\beta$-segregation; (a4) formation of B2 and $\alpha_{2} / y$ lamellae

(b1) - (b4): $x \geq 0.3 a t . \%$; (b1) formation of $\beta$ phase; (b2) formation of $\alpha$ phase and segregation of $\mathrm{Si}$;

(b3) formation of $\mathrm{Ti}_{5} \mathrm{Si}_{3}$ at the interface of $\alpha$ colonies; (b4) formation of $\mathrm{B} 2$ and $\alpha_{2} / \mathrm{Y}$ lamellae

structure [Fig. 6(a4)]. Consequently, the microstructure of the Ti48Al6NbxSi alloys with lower content of silicon consists of $\alpha_{2} / \gamma$ lamella and B2 phase.

When the content of silicon is $\geq 0.3$ at. $\%$ as shown in Fig. 6(b1-b4), the initial two stages of the solidification process of the TiAl alloy are the same as that when the content of silicon is $<0.3$ at.\%. During the solidification process, $\beta$ phase with higher solubility of $\mathrm{Nb}$ also primarily precipitates from the alloy melt [Fig. 6(b1)], and then $\alpha$ phase with $\beta$-segregation forms by the peritectic reaction, as shown in Fig. 6(b2). After that, $\mathrm{Nb}$ atoms segregate in $\alpha$ phase and $\mathrm{Si}$ atoms are squeezed from $\alpha$ phase and segregated in the liquid melt between the dendrites. $\mathrm{Ti}_{5} \mathrm{Si}_{3}$ phase then forms at the interface of the $\alpha$ colonies [Fig. 6(b3)]. After the melt is consumed, $\alpha$ colonies with $\beta$-segreagtion are transformed into $\alpha_{2} / \gamma$ lamellae by the solid-state phase transformation, and $\beta$-segregations transfer into B2 phase [Fig. 6(b4)]. Finally, the microstructure of the Ti48Al6 NbxSi alloys with higher content of silicon consists of $\alpha_{2} / \gamma$ lamella, B2 phase and $\mathrm{Ti}_{5} \mathrm{Si}_{3}$ phase.

Figure 7 shows the relationship between the compressive strength of the alloys and volume fraction of B2 phase and $\mathrm{Ti}_{5} \mathrm{Si}_{3}$ phase. It shows that the decrease of $\mathrm{B} 2$ phase and the formation of $\mathrm{Ti}_{5} \mathrm{Si}_{3}$ phase lead to the increase of compressive strength and the decrease of fracture strain of the Ti48Al6NbxSi alloys. When the addition of silicon is less than 0.3 at. $\%$, silicon acts as an interstitial solid solution element in the Ti48Al6 Nbx Si alloys. Though the addition of silicon decreases the amount of B2 phase, the ultimate strength of the alloys at room temperature is increased for the solid solution strengthening. Meanwhile, the interstitial silicon atoms lead to lattice distortion of alloys, which will increase the resistance of the dislocation motion, and make the slipping deformation of alloys more difficult, therefore decreasing the fracture strain of the alloys. When the content of silicon is $0.3 \mathrm{at} . \%$, the formation of $\mathrm{Ti}_{5} \mathrm{Si}_{3}$ phase can dissolve a certain amount of $\mathrm{Nb}$

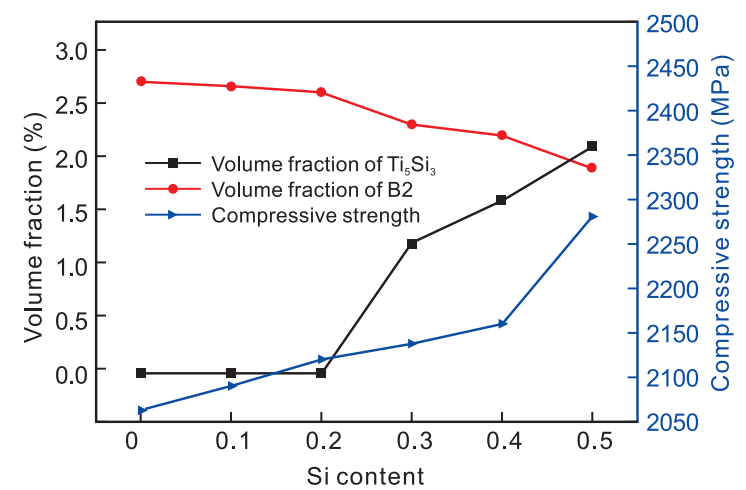

Fig. 7: Relationship between compressive strength of alloys and volume fraction of $\mathrm{B} 2$ and $\mathrm{Ti}_{5} \mathrm{Si}_{3}$ phase

atoms, and leads to a decrease in the amount of B2 phase. At this time, the formed $\mathrm{Ti}_{5} \mathrm{Si}_{3}$ phase acts as the secondary phase, and exhibits the secondary phase strengthening mechanism in the alloy. When continuing to increase the content of silicon to 0.4 at. $\%$ and 0.5 at.\%, the amount of B2 phase decreases while that of $\mathrm{Ti}_{5} \mathrm{Si}_{3}$ phase further increases. Thus, the secondary phase strengthening mechanism caused by Ti5Si3 phase is still the main strengthening mechanism. Therefore, the ultimate strength of the TiAl alloy still increases with increasing of the silicon. At the same time, the deformation of silicide phase cannot coordinate with that of the matrix alloy during the compression test, and the deformation of the alloys is much harder due to the formation of silicide phase. Consequently, the fracture strain of alloys is decreasing with addition of silicon.

Therefore, the strengthening mechanism of Ti48A16NbxSi alloys with different contents of silicon is solid solution strengthening when the addition of silicon is less than 0.3at.\%, and changed to the combination of solid solution strengthening and secondary phase strengthening when the addition of silicon is no less than $0.3 \mathrm{at} . \%$. 


\section{Conclusions}

Ti48A16Nb $x$ Si (at.\%, $x=0,0.1,0.2,0.3,0.4$ and 0.5 ) alloys are prepared by vacuum arc melting, and the microstructure evolution, phase constitution, and mechanical properties of the alloys were systematically studied. Several conclusions can be drawn as follows:

(1) The addition of silicon, a $\alpha$ phase stabilizing element, leads to a decrease in the amount of $\gamma$ phase and an increase in the amount of $\alpha_{2}$ phase.

(2) The alloys consist of $\gamma$-TiAl phase, $\alpha_{2}-\mathrm{Ti}_{3} \mathrm{Al}$ phase and B2 phase when $\mathrm{Si}$ addition is less than $0.3 \mathrm{at} . \%$, and $\mathrm{Ti}_{5} \mathrm{Si}_{3}$ silicide phase is formed when the addition of silicon is no less than 0.3 at. $\%$, which can decrease the volume fraction of B2 phase. Furthermore, the formation of silicide decreases the amount of $\mathrm{Nb}$ dissolved in the TiAl matrix.

(3) Compressive tests show that the compressive strength increases from 2,063 MPa to 2,281 $\mathrm{MPa}$ when $\mathrm{Si}$ addition increases from 0 to 0.5 at. $\%$, while the fracture strain has a decreasing tendency from $34.7 \%$ to $30.8 \%$. The increase of strength and decrease of fracture strain are attributed to the decrease of $\mathrm{B} 2$ phase and the formation of $\mathrm{Ti}_{5} \mathrm{Si}_{3}$ phase.

(4) The strengthening mechanism is changed from solid solution strengthening when the addition of silicon is less than 0.3 at.\% to the combination of solid solution strengthening and secondary phase strengthening when the addition of silicon is no less than 0.3 at. $\%$.

\section{Acknowledgments}

This work was financially supported by the National Natural Science Foundation of China (Grant Nos. 51825401, 51971121, 52001114), the Scientific Research Fund of State Key Laboratory of Materials Processing and Die \& Mould Technology (Grant No. P2020-023), and Henan Provincial Department of Science and Technology Research Project (Grant No. 182102110096).

\section{References}

[1] Bewlay B P, Nag S, Suzuki A, et al. TiAl alloys in commercia aircraft engines. High Temperature Technology, 2016, 33(4-5): 549-559.

[2] Bao C L, Zhang S Q, Ren $Y Y$, et al. Research progress on refractory composition and deformability of shell molds for TiAl alloy castings. China Foundry, 2018, 15(1): 1-10.

[3] Fang H Z, Chen R R, Chen X Y, et al. Effect of Ta element on microstructure formation and mechanical properties of high-Nb TiAl alloys. Intermetallics, 2019, 104: 43-51.

[4] Liu X W, Zhang Z L, Du H, et al. Effect of hydrogen on mold filling behavior of TiAl alloy. Intermetallics, 2014, 55: 102-107.

[5] Zhao J, Zhang Z Y, Liu S B, et al. Elimination of misrun and gas hole defects of investment casting TiAl alloy turbocharger based on numerical simulation and experimental study. China Foundry, 2020, 17(1): 29-34.

[6] Liu X W, Liu F C, Du H, et al. Effect of hydrogen on interfacia reaction between TiAl alloy melt and graphite mold. Intermetallics, 2014, 53: 107-111.

[7] Chen Z X, Ding H S, Chen R R, et al. An innovative method for the microstructural modification of TiAl alloy solidified via direct electric current application. Journal of Materials Science \& Technology, 2019, 35(1): 23-28.
[8] Jiang H R, Wang Z L, Ma W S, et al. Effects of $\mathrm{Nb}$ and Si on high temperature oxidation of TiAl. Transactions of Nonferrous Metals Society of China, 2008, 18(3): 512-517.

[9] Rios O, Goyel S, Kesler M S, et al. An evaluation of hightemperature phase stability in the Ti-Al-Nb system. Scripta Materialia, 2009, 60(3): 156-159.

[10] Yang L, Chai L H, Wang Y L, et al. Precipitates in high-Nb TiAl alloyed with Si. Materials Letters, 2015, 154: 8-11.

[11] Gui W Y, Liang Y F, Hao G J, et al. High Nb-TiAl-based porous composite with hierarchical micro-pore structure for high temperature applications. Journal of Alloys and Compounds, 2018, 744: 463-469.

[12] Saage H, Huang A J, Hu D, et al. Microstructures and tensile properties of massively transformed and aged Ti46Al8 $\mathrm{Nb}$ and Ti46AI8Ta alloys. Intermetallics, 2009, 17(1-2): 0-38.

[13] Wang J W, Wang Y, Liu Y, et al. Densification and microstructural evolution of a high niobium containing TiAl alloy consolidated by spark plasma sintering. Intermetallics, 2015, 64: 70-77.

[14] Zhou Y, Wang J Q, Zhang B, et al. High-temperature fatigue property of Ti46Al8 $\mathrm{Nb}$ alloy with the fully lamellar microstructure. Intermetallics, 2012, 24: 7-14.

[15] Zhou C X, Zeng F P, Liu B, et al. Effects of Si on microstructures and high temperature properties of beta stabilized TiAl alloy. Materials Transactions, 2016, 57(3): 461-465.

[16] Mathabathe M N, Bolokang A S, Govender G, et al. The vacuum melted $\mathrm{y}-\mathrm{TiAl}(\mathrm{Nb}, \mathrm{Cr}, \mathrm{Si})$-doped alloys and their cyclic oxidation properties. Vacuum, 2018, 154: 82-89.

[17] Zhang $\mathrm{Y}$, Wang $\mathrm{X} \mathrm{P}$, Kong $\mathrm{F} \mathrm{T}$, et al. A high-performance $\beta$-solidifying TiAl alloy sheet: Multi-type lamellar microstructure and phase transformation. Materials Characterization, 2018, 138: $136-144$.

[18] Jiménez J A, Carsí M, Frommeyer G, et al. The effect of microstructure on the creep behavior of the Ti-46Al-1Mo-0.2Si alloy. Intermetallics, 2005, 13(10): 1021-1029.

[19] Yang L, Gao S B, Wang Y L, et al. Effect of Si addition on the microstructure and room temperature tensile properties of high Nb-TiAl alloys. Acta Metallurgica Sinica, 2015, 51(7): 859-865. (In Chinese)

[20] Kim S W, Wang P, Oh M H, et al. Mechanical properties of Siand C-doped directionally solidified TiAl-Nb alloys. Intermetallics, 2004, 12(5): 499-509.

[21] Du H L, Datta P K, Griffin D, et al. Oxidation and sulfidation behavior of AITiN-coated Ti-46.7Al-1.9W-0.5Si intermetallic with $\mathrm{CrN}$ and $\mathrm{NbN}$ diffusion barriers at $850{ }^{\circ} \mathrm{C}$. Oxidation of Metals, 2003, 60(1): 29-46

[22] Liu Z M, Liu Z J, Ji S, et al. Research progress in preparation and application of $\mathrm{Ti}_{5} \mathrm{Si}_{3}$. Materials Reports, 2019, 33(Z2): 175-180. (In Chinese)

[23] Johnson D R, Inui H, Yamaguchi M. Directional solidification and microstructural control of the $\mathrm{TiAl} / \mathrm{Ti}_{3} \mathrm{Al}$ lamellar microstructure in TiAl-Si alloys. Acta Materialia, 1996, 44(6): 2523-2535.

[24] Lee H N, Johnson D R, Inui H, et al. A composition window in the TiAl-Mo-Si system suitable for lamellar structure control through seeding and directional solidification. Materials Science and Engineering A, 2002, 329-331: 19-24.

[25] Fan J L, Liu J X, Wu S, et al. Microstructure formation and interface characteristics of directionally solidified TiAl-Si alloys in alumina crucibles with a new $\mathrm{Y}_{2} \mathrm{O}_{3}$ skull-aided technology. Scientific Reports, 2017, 7: 45198.

[26] Fan J L, Li X Z, Su Y Q, et al. Effect of thermal stabilization on microstructure and mechanical property of directionally solidified Ti-46Al-0.5W-0.5Si alloy. Transactions of Nonferrous Metals Society of China, 2012, 22(5): 1073-1080.

[27] Fan J L, Li X Z, Su Y Q, et al. Microstructure evolution of directionally solidified Ti-46Al-0.5W-0.5Si alloy. Journal of Crystal Growth, 2011, 337(1): 52-59. 